American Journal of Environmental Sciences 3 (3): 98-105, 2007

ISSN 1553-345X

(C) 2007 Science Publications

\title{
Evaluation of Nitrogen Non-Point Sources in Po River Near Turin
}

\author{
Giuseppe Genon, Franco Marchese \\ DITAG - Dipartimento del Territorio, dell'Ambiente e delle Geotecnologie \\ Politecnico di Torino - C.so Duca degli Abruzzi 24, 10129 - Torino, Italy
}

\begin{abstract}
The non-point hydraulic and nitrogen loads in the stretch of Po river upstream and downstream from the city of Turin have been investigated, on the basis of regular data concerning quality and flow rates in the river in different periods of a reference year.

The collected data have been organized in terms of hydraulic and mass balances, taking into account input points, affluents and withdrawals, and the missing terms as concern non-point loads or transfer phenomena with surrounding banks and connected aquifers have been identified.From the nitrogen speciation it was possible to distinguish between different contributions to river load, and to estimate presence of agricultural loads, run-off phenomena from impervious urban areas, aquifer connections. All these information can be useful for a better assessment of the surrounding territory in order to improve river quality for different uses.
\end{abstract}

Keywords: River model, nitrogen balance, non-point sources, sampling, river quality

\section{INTRODUCTION}

In the treatment plant of the city of Turin (SMAT plant) the city wastewater (one million inhabitants) and a high number of surrounding communities are treated; the treated flow is introduced in Po river downstream of the city, in Castiglione territory.

For the present study considered year (2003), the total nitrogen removal rate was 4200 tons, and the residual quantity that has been discharged in the river was 3900 tons, with an amount of 3100 in nitric form. This flow rate in any case will be shortly strongly decreased in account of final activation of denitrification stage.

The influence of nitrogen punctual sources on the water quality in the river stretch downstream of input point has been studied in the past [1], and it could be calculated on the basis of introduced load. On the contrary very little are the indications about effects deriving from non-point sources, and chiefly the ones corresponding to wash-out of rain impervious surfaces of urban Turin area. The city of Turin rain waters, after collection with a separate sewing systems flow in river Po. The treatment necessity for this flux and the urgency of this intervention will be defined after the obtention of a complete knowledge of real load in comparison total non-point load. This estimation can be done for some pollutants, as example heavy metals, but on the contrary it is very difficult for nitrogen.

The aim of this study was to individuate the non-point nitrogen flows directly or indirectly introduced in the urban stretch of the river, and to identify if it is possible their origin [2]. In order to do this, all the pertaining past data have been revised, and the useful ones have been chosen in order to define a mass balance for loads calculation. In order to be able to evaluate the effects of urban area, in the study large river stretch upstream and downstream from the city has been considered.

\section{MATERIALS AND METHODS}

Considered river stretch: The head of the Po river is located in West Alps in Piedmont, it cross the Padana plain and it flows in the Adriatic Sea after a run of 652 $\mathrm{km}$. After $100 \mathrm{~km}$ from the head of the river arrives to the place of the city of Turin; the considered river stretch for this study was comprised between $\mathrm{km} 47$ and $\mathrm{km} 127$ from the source. In fig. 1 the studied sections are reported, together with affluents, withdrawals, input point, and their distances.

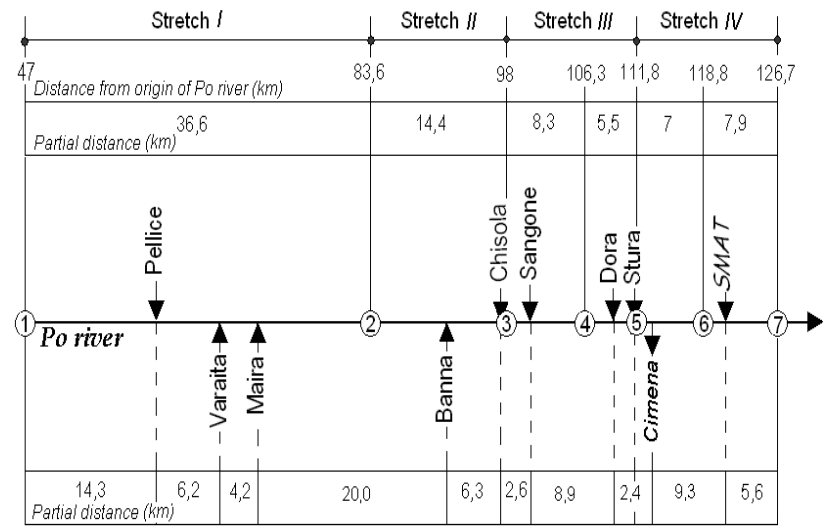

Fig. 1 : Hydraulic scheme of considered river stretch Sections : $1=$ Cardè; $2=$ Carignano; $3=$ Moncalieri; 4 $=$ Torino; $5=$ San Mauro; $6=$ Castiglione; $7=$ Brandizzo

Corresponding Author: Giuseppe Genon, DITAG (Dipartimento del Territorio, dell'Ambiente e delle Geotecnologie) Politecnico di Torino, c.so Duca degli Abruzzi 24, 10129 - Torino, Italy 
In the first upstream part, from section 1 to section 2 and nearly to section 3 , it chiefly runs through rural areas. On the contrary populated and industrial zones are only present from $\mathrm{km} 90$ more or less. The zone corresponding to urban area is comprised between Section 3 (Moncalieri) and Section 5 (San Mauro). The river flows along a hills belt bounding the Turin city in its South West part. The larger extension of the city is in the left bank, between the confluence of the Sangone tributary and the Stura one, and it is crossed from Dora river. On the right bank the urban development was limited to a narrow zone before extension on the hills. The Section 4 (Torino) is located more or less at the centre of urban stretch.

Downstream from the city immediately after Section 5 (San Mauro) the hydraulic scheme is complicated by the Cimena channel derivation, and input from wastewater treatment plant of Turin district (SMAT), after Section 6 (Castiglione). In account of Cimena channel derivation the river flow rate is strongly reduced, and in some seasonal periods the treatment plant discharge can be of the same order of magnitude of receiving body flow rate. Between section 3 (Moncalieri) and Section 7 (Brandizzo) theoretically there are not conveyed untreated loads, with exception of the flows deriving from rain water collection obtained with the dedicated sewer network of the city.

\section{Available data}

We chiefly used monitoring data of Piedmont Region, but also data of different origin. The data have reference to year 2003, as during this year we found the maximum of available data.

\section{Flow rate data}

The daily flow rates of all Po sections are available, with exception of Section 7 (Brandizzo); also for affluents it was possible to obtain these data, but on some cases they are measured in sections different from closure section or surrounding points. For the Moncalieri Po Station (Section 3) the flow rate data are referred to a different Section from the analytical samples one; besides they are not part of the Regional Monitoring Network.

For SMAT treatment plant we used available data of monthly mean flow rate.

It was not possible to obtain data about Cimena channel.

\section{$\underline{\text { Rainfall data }}$}

For different stations on the regional territory it was possible to find data (rain $\mathrm{mm}$ every $10 \mathrm{~min}$.).

\section{Analytical data}

For some Sections monitored physico-chemical data automatically taken together with flow rate value are at disposal, i.e. temperature, $\mathrm{pH}$, electrical conductivity, dissolved oxygen. On the contrary the information about chemical characterization are point data with monthly frequency: they are at disposal for all the affluents and study Sections, with exception of Section 6 (Castiglione). For the treatment plant the mean monthly values are known, and also more detailed information.

There is not analytical information about Cimena channel.

An inconvenient aspect arises from the consideration that the samplings of each month have been realized in different days, and not in each case in the same day for the different sampling stations. Moreover for affluents the sampling station in some cases doesn't correspond with closure section or the section where the flow rate was measured.

The parameters taken into account in the study were: $\mathrm{pH}$, conductivity, chlorides, sulfates, total nitrogen, nitric nitrogen, ammonia nitrogen, phosphorus. In the present paper we will present only the data concerning nitrogen different forms.

Data processing and utilized balances

The hydraulic balance equation for a generic downstream river section is:

$\mathrm{Q}_{\mathrm{v}}=\mathrm{Q}_{\mathrm{m}}+\sum \mathrm{F}_{\mathrm{i}}+\sum \mathrm{Qp}_{\mathrm{i}}+\sum \mathrm{Qr}_{\mathrm{i}}+\sum \mathrm{Qfe}_{\mathrm{i}}-\sum \mathrm{Qd}_{\mathrm{i}}-\sum$ $\mathrm{Qfu}_{\mathrm{i}}$

where:

$\mathrm{Q}_{\mathrm{v}}=$ downstream river flow rate

$\mathrm{Q}_{\mathrm{m}}=$ upstream river flow rate

$\mathrm{F}_{\mathrm{i}}=$ affluent flow rate

$\mathrm{Q}_{\mathrm{pi}}=$ input point flow rate

$\mathrm{Q}_{\mathrm{ri}}=$ surface streaming flow rate in direction of river

$\mathrm{Q}_{\mathrm{fei}}=$ underground draining flow rate

$\mathrm{Q}_{\text {fui }}=$ flow rate from river to underground

$\mathrm{Q}_{\mathrm{di}}=$ derivation flow rate for irrigation, industrial use, hydroelectric plants, drinking

As it is impossible to solve the balance equation for all interesting stations as a consequence of difficulty to determine all the unknown terms, we used a more simplified balance equation

$\mathrm{Q}_{\mathrm{v}}=\mathrm{Q}_{\mathrm{m}}+\sum \mathrm{F}_{\mathrm{i}}-\sum \mathrm{Qd}_{\mathrm{i}}+/-\sum \mathrm{Q}_{\text {Diff }}$

where the term $+/-\sum \mathrm{Q}_{\text {Diff }}$ represents the net nonpoint flow rates; in this term all the water exchanges with underground, surface streaming flows and difficult to estimate non-point fluxes have been included.

The balance resolution leads to flow rate improvements in the stretch between two stations in account of these fluxes, or its decreases if withdrawal from river are prevailing.

The balance has been applied in cases where it was possible with daily data, as an alternative with aggregated data as monthly mean flow rates. The net non-point flow rates that was possible calculate from the balances have been indirectly verified, for upstream 
Turin river stretch, but means of comparison with inflow and down flow year volumes that have been calculated on the basis of rain quantities, and river basin characteristics. For the stretches Carignano-Cardè and Carignano-Moncalieri, the volumes that was possible to determine were respectively $75 \%$ and $92 \%$ of the values that were estimated from rain data processing. From the simplified hydraulic balance equation it has been possible to derivate the mass balance equation that was used in order to define the mass loads in a generic downstream section:

$\mathrm{Q}_{\mathrm{v}} \mathrm{C}_{\mathrm{v}}=\mathrm{Q}_{\mathrm{m}} \mathrm{C}_{\mathrm{m}}+\sum \mathrm{F}_{\mathrm{i}} \mathrm{C}_{\mathrm{i}}-\sum \mathrm{Qd}_{\mathrm{i}} \mathrm{Cd}_{\mathrm{i}}+/-\sum \mathrm{Q}_{\text {Diff }} \mathrm{C}_{\text {Diff }}$

where together with hydraulic flow rates concentrations are considered. The term +/- $\sum \mathbf{Q}_{\text {Diff }} \mathbf{C}_{\text {Diff }}$ represents the net load deriving from non-point introductions or losses in the considered stretch. The term $\mathbf{C}_{\text {Diff }}$ indicates the concentration that can estimated for the net flow.

In account of the fact of the non-conservative nature of dissolved nitrogen, in the net load term it will be included also the contribution deriving from chemical and biological removal phenomena, or vegetative uptakes [3]. If the net load value is negative, on the basis of the known net non-point exchanged mass flow rate it was possible in some cases to obtain semiquantitative estimations of nitrogen degradation or uptake.

The point load data have not been evaluated, as the analytical data at disposal are referred to different month days for different sections and different affluents. Therefore for the calculation of the nitrogen net loads in the equation we introduced mean monthly flow rates, and for concentration values instead of point values it was used the mean value of two following samplings, obviously by considering a linear variation of concentration between two following determinations. In order to be able to have a direct comparison the net non-point loads have been also referred to the river length unit.

Some other quantitative considerations have been introduced about year mean values of volumes and loads [4].

\section{Individuation and choosing of considered stretches:}

Four different characteristics stretches have been chosen to represent different aspects, namely

I Cardè Carignano

II Carignano Moncalieri

III Moncalieri S. Mauro

IV San Mauro Brandizzo

In the first two stretches we could recognize a territorial situation with an agricultural vocation; the third one represents the influence of Turin and other urbanization areas; the last one shows important aspects of interest in account of reduced flow rate and wastewater treatment plant discharge influence.

The third stretch has non been further divided has it was difficult to evaluate the different effect of city load in the two different stretches Moncalieri -Torino and Torino - San Mauro. Moreover it has been evaluated that the flow rate values concerning Moncalieri are not completely reliable, so the consideration of a shorter stretch could have an higher influence on obtained results; lastly, by this definition, with exclusion of first one all the stretches have a similar river length. The data concerning section 4 (Torino) can be used for verification purposes.

The decision to limit the investigated area to the section 7 (Brandizzo) where there are not at disposal flow rate data is unavoidable, as the downstream hydraulic situation is absolutely more complex, and consequently it should be completely impossible to establish reliable mass balances.

Methods for evaluation of lacking flow rate values: For Cimena channel and Po river in Brandizzo it was necessary to completely define flow rate values, and for Po river at Moncalieri station it was necessary to revise the measured values.

In order to evaluate the unknown flow rate values, it was used a chloride mass balance, by considering the conservative nature of this parameter. This assumption was justified from the observation that this procedure has been previously used by Authors with satisfying results in the verification of flow rate balances in stretch upstream from Moncalieri.

In order to calculate flow rates for Cimena channel, the balance equations are:

$\mathrm{Q}_{\text {Cimena }}=\mathrm{Q}_{\text {Sect. 5 }}+\sum \mathrm{Q}_{\text {Diff }}-\mathrm{Q}_{\text {Sect. 6 }}$

$\mathrm{Q}_{\text {Sect.5 }}\left[\mathrm{Cl}^{-}\right]_{\text {Sect. } 5}=\mathrm{Q}_{\text {Sect. } 6}\left[\mathrm{Cl}^{-}\right]_{\text {Sect. } 6}+\mathrm{Q}_{\text {Cimena }}\left[\mathrm{Cl}^{-}\right]$

Cimena $+\sum \mathrm{Q}_{\text {Diff }}\left[\mathrm{Cl}^{-}\right]_{\text {Diff }}$

The chlorides concentration of Cimena channel can be taken as equal to the concentration in section 5 (San Mauro), whereas the value in section 6 (Castiglione) is not known. We have three parameters to be determined, and the system cannot be solved. The net non-point flow rate in stretch $5-6$ is part of the measured value in Castiglione station. The possible non-point chloride input presents a very low influence in chloride concentration in Castiglione, and so this concentration can be considered corresponding to the value determined for San Mauro. This simplification corresponds to the adoption of the hydraulic flow rate balance only, by assuming that in the flow rate value determined for Castiglione the non-point input, that really cannot be known for this stretch, are included.

In order to determine the Brandizzo section river flow rate, the balance equations are:

$\mathrm{Q}_{\text {Sect. } 7}=\mathrm{Q}_{\text {Sect. 6 }}+\mathrm{Q}_{\text {SMAT }}+\sum \mathrm{Q}_{\text {Diff }}$ 
Am. J. Environ. Sci., 3 (3): 98-105, 2007

Table 1: Monthly flow rates for affluents, withdrawals, wastewater

\begin{tabular}{lcccccccccc}
\hline & Pellice & Varaita & Maira & Banna & Chisola & Sangone & Dora & Stura & Cimena & SMAT \\
\hline January & $\left(\mathrm{m}^{3} \mathrm{~s}^{-1}\right)$ & $\left(\mathrm{m}^{3} \mathrm{~s}^{-1}\right)$ & $\left(\mathrm{m}^{3} \mathrm{~s}^{-1}\right)$ & $\left(\mathrm{m}^{3} \mathrm{~s}^{-1}\right)$ & $\left(\mathrm{m}^{3} \mathrm{~s}^{-1}\right)$ & $\left(\mathrm{m}^{3} \mathrm{~s}^{-1}\right)$ & $\left(\mathrm{m}^{3} \mathrm{~s}^{-1}\right)$ & $\left(\mathrm{m}^{3} \mathrm{~s}^{-1}\right)$ & $\left(\mathrm{m}^{3} \mathrm{~s}^{-1}\right)$ & $\left(\mathrm{m}^{3} \mathrm{~s}^{-1}\right)$ \\
\hline February & 8.01 & 6.22 & 17.15 & 2.11 & 5.62 & 7.16 & 21.30 & 4.55 & -72.0 & 5.93 \\
\hline March & 4.30 & 4.41 & 12.83 & 0.78 & 4.27 & 2.88 & 18.60 & 5.14 & -84.4 & 5.77 \\
\hline April & 4.45 & 4.46 & 14.64 & 0.54 & 3.30 & 3.66 & 20.10 & 4.66 & -94.2 & 5.85 \\
\hline May & 5.47 & 5.33 & 14.21 & 0.55 & 4.87 & 2.58 & 20.90 & 10.70 & -106.1 & 6.11 \\
\hline June & 17.97 & 8.86 & 23.49 & 0.50 & 4.50 & 4.96 & 36.80 & 20.70 & -140.6 & 6.32 \\
\hline July & 4.73 & 4.84 & 5.59 & 0.24 & 2.42 & 1.13 & 24.60 & 23.65 & -135.0 & 6.98 \\
\hline August & 1.46 & 0.45 & 0.30 & 0.15 & 0.70 & 1.47 & 6.55 & 5.14 & -18.9 & 6.87 \\
\hline September & 1.33 & 0.21 & 0.29 & 0.18 & 0.57 & 1.42 & 3.16 & 6.16 & -13.3 & 5.41 \\
\hline October & 1.06 & 0.39 & 0.60 & 0.19 & 1.19 & 1.84 & 7.20 & 10.17 & -15.7 & 5.94 \\
\hline November & 0.99 & 2.33 & 3.69 & 0.22 & 1.61 & 1.01 & 12.10 & 8.68 & -33.0 & 5.79 \\
\hline December & 1.55 & 4.77 & 7.56 & 0.73 & 3.89 & 1.60 & 14.00 & 17.30 & -55.7 & 6.67 \\
\hline annual average & 15.9 & 6.53 & 10.36 & 2.69 & 11.43 & 11.62 & 18.10 & 39.00 & -89.1 & 6.77 \\
\hline \multicolumn{1}{c}{${ }^{2}$ calculated values } & $\mathbf{5 . 6 0}$ & $\mathbf{4 . 0 7}$ & $\mathbf{9 . 2 3}$ & $\mathbf{0 . 7 4}$ & $\mathbf{3 . 7 0}$ & $\mathbf{3 . 4 4}$ & $\mathbf{1 6 . 9 5}$ & $\mathbf{1 2 . 9 9}$ & $\mathbf{- 7 1 . 5}$ & $\mathbf{6 . 2 0}$ \\
\hline
\end{tabular}

$Q_{\text {Sect. } 7}\left[\mathrm{Cl}^{-}\right]_{\text {Sect. } 7}=Q_{\text {Sect. } 6}\left[\mathrm{Cl}^{-}\right]$Sect. $6+Q_{\text {SMAT }}\left[\mathrm{Cl}^{-}\right]$ SMAT $+\sum \mathrm{Q}_{\text {Diff }}\left[\mathrm{Cl}^{-}\right]_{\text {Diff }}$

By assuming the same concentration for chlorides in Castiglione (Section 6) and S. Mauro (Section 5), and by assuming for the value of chlorides in non-point input a value equal to the mean chlorides concentration in underground waters measured in this area (this value has been experimentally determined), the system can be solved.

The equation and this specific solution cases have been considered by using mean monthly values for flow rate and also mean values for concentrations, as previously indicated.

As concerns Moncalieri section, the data have been aggregated in mean monthly values, compared and mediated with the values that were obtained by means of a chlorides balance for section 4 (Torino).

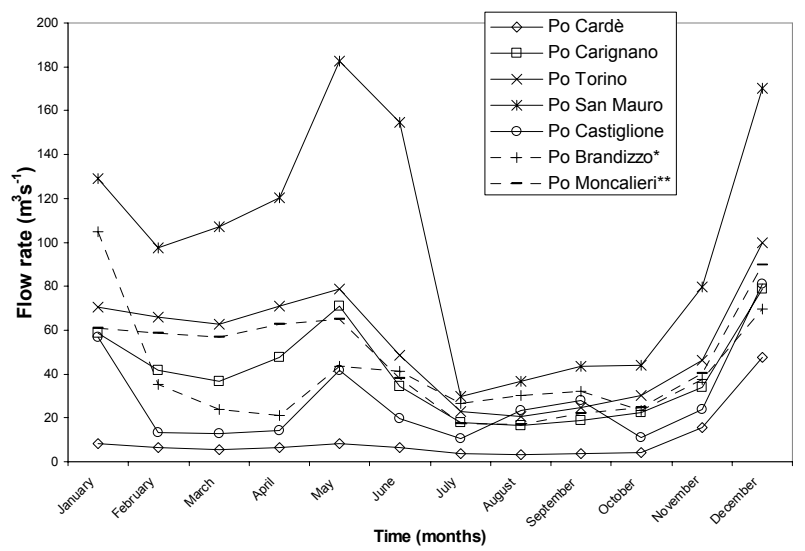

Fig. 2 : Monthly flow rates in the Po river

\section{RESULTS AND DISCUSSION}

The values for different months of mean flow rate are reported for the considered Sections in fig. 2: the values concerning Section 7 (Brandizzo) have been calculated, while the values for Section 3 (Moncalieri) have been determined by using the above described procedure. It is possible to observe two maximum values corresponding to periods of April - May and November - December, for all Sections.

In table 1 it is possible to observe the monthly and yearly mean values of affluent flow rates, discharges and derivations (the Cimena channel values have been calculated, the derivations present a negative sign).

It is interesting to note the very high value for derivation flow rate of Cimena channel.

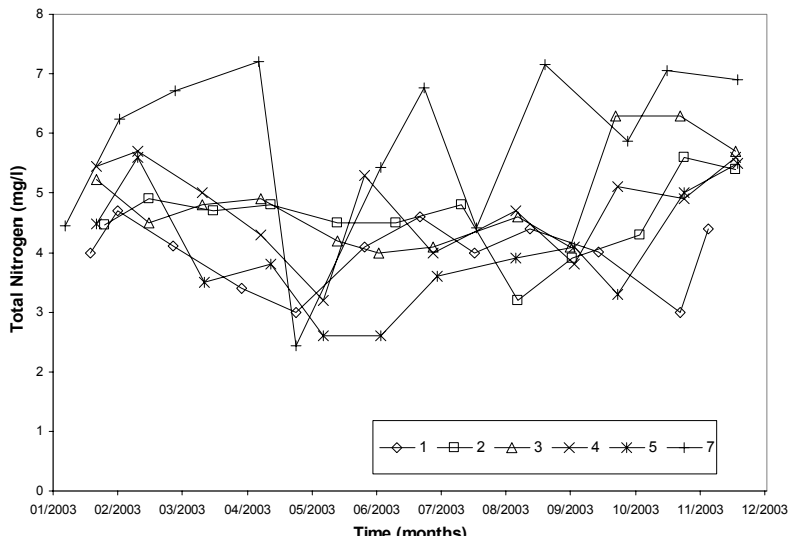

Fig. 3a : Total nitrogen concentration in Po river 


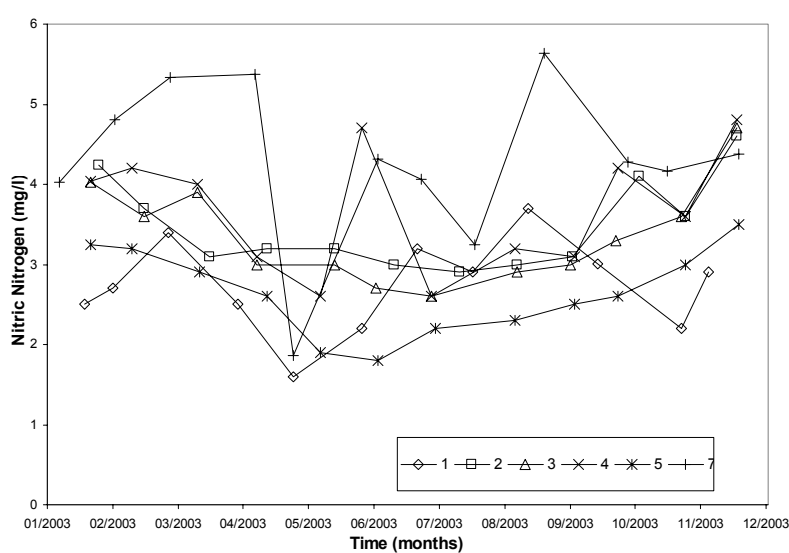

Fig. $3 \mathrm{~b}$ : Nitric nitrogen concentration in Po river

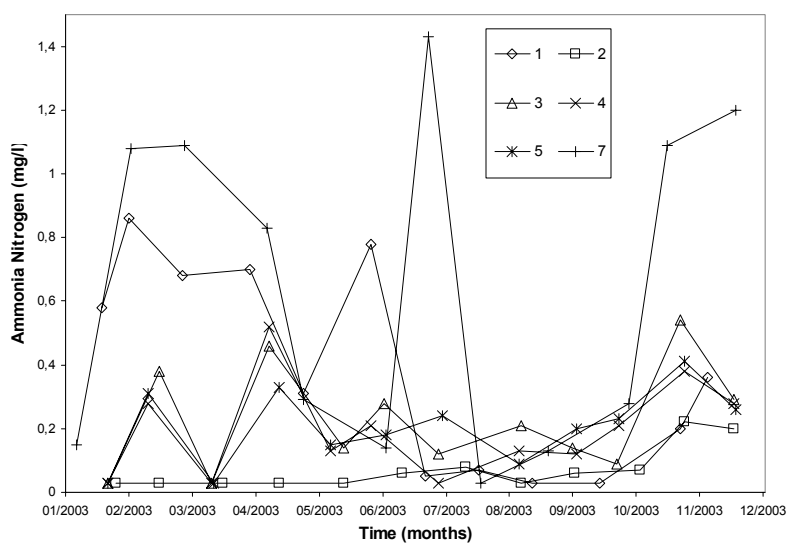

Fig. 3c : Ammonia nitrogen concentration in Po river
In fig. 3 it is shown the time behavior of point concentrations for different nitrogen forms. In absolute terms the higher values can be observed in Section 7 (Brandizzo) as a consequence of wastewater treatment plant discharge, taking into account that the mean residual concentrations from the plant in total, nitric, ammonia nitrogen are respectively $20,16,3 \mathrm{mg} / \mathrm{l}$.

As these concentrations and also discharged flow rate are generally constant, the receiving body impact is totally dependent on its flow rate, and in general it is possible to observe that concentration values present an inverse relationship with river flow rate. The values for November and December show an exception to this observation, as both concentration and flow rates are quite high. As a percentage the higher variations can be observed for ammonia nitrogen parameter.

The calculated (mass balance) value for non-point volumetric flow rate for the considered stretches can be seen in fig. 4: higher values can be observed in stretch III (Moncalieri - S. Mauro), while in correspondence with flow rate peaks of May and December for stretches II and IV significant negative values have been obtained.

In fig. 5 the non-point loads for different nitrogen forms as previously calculated are reported: as concerns total and nitric nitrogen, highest values can be observed in stretch III, for ammonia in stretches II and IV; chiefly in stretches II and IV it is possible to observe negative values for total and nitric nitrogen; for ammonia, the negative loads are evident in stretches I (first part of the year) and IV. The stretch I presents in all periods positive net values for non-point total and nitric loads.

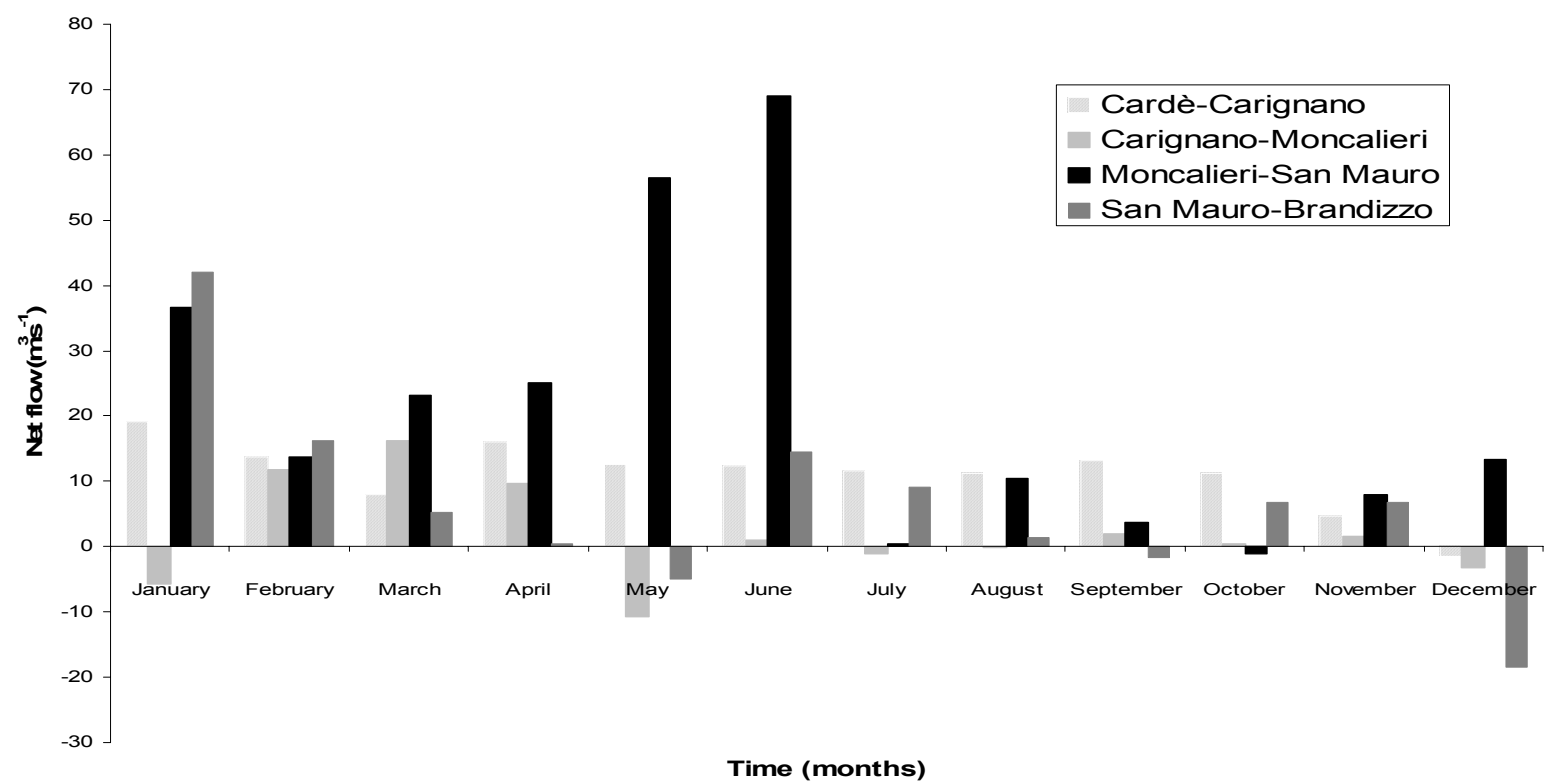

Fig. 4 : Net non-point flows 


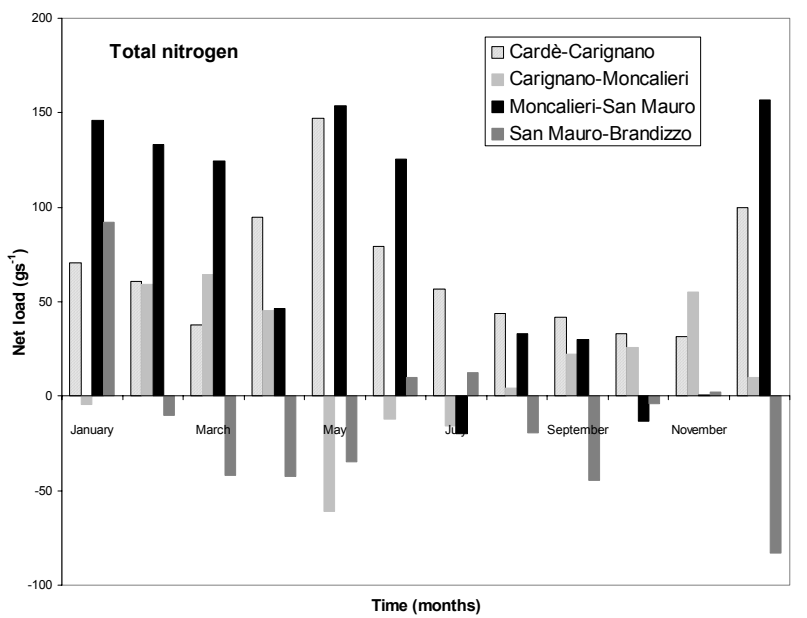

Fig. 5a : Net non-point loads of total nitrogen

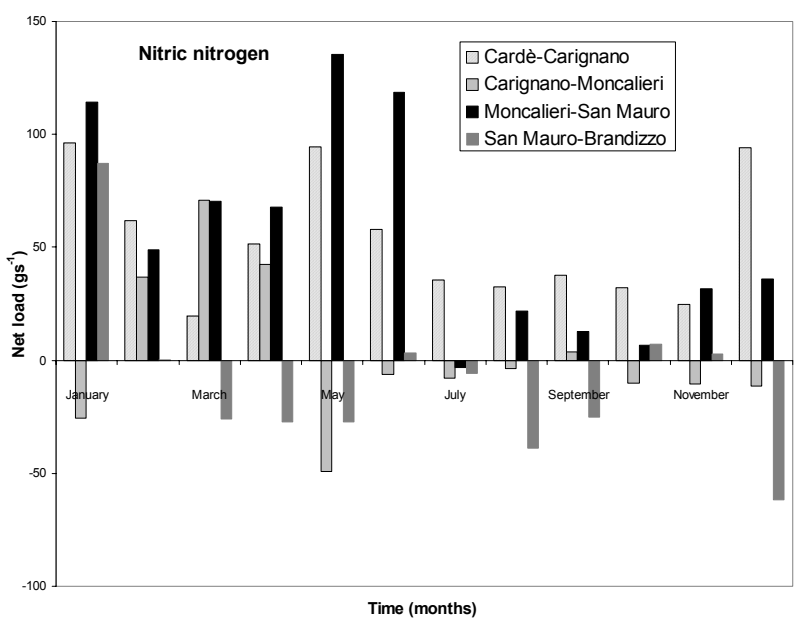

Fig. $5 b$ : Net non-point loads of nitric nitrogen

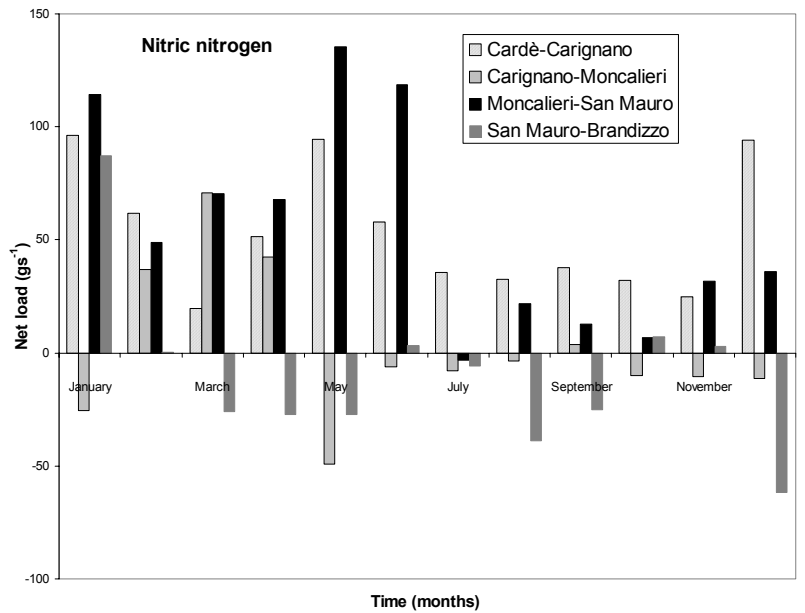

Fig. $5 \mathrm{c}$ : Net non-point loads of ammonia nitrogen

In table 2 the yearly mean values for net non-point volumetric flow rates and nitrogen loads are reported; there is also an indication of total year contribution, and specific values for each $\mathrm{km}$ of river length.
It can be observed the presence of decidedly higher values for total and nitric nitrogen loads in stretch III (Moncalieri - San. Mauro), chiefly if non-point specific loads are considered. These values can be explained if we consider the distributed high loads deriving from the hills in the right bank and run-off phenomena. The total quantity that in this urban stretch is introduced in the river, is a little more that the quantity introduced downstream from the SMAT discharge: it is in any case quite impossible to distinguish between the nitrogen load deriving from urban area and that one that is connected with hills zone run-off.

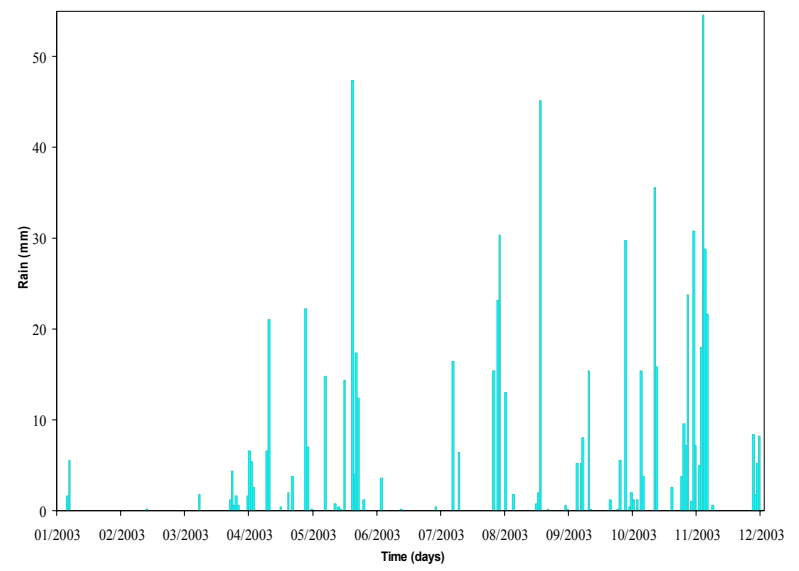

Fig. 6 : Precipitation in Turin

On the annual balance in this stretch the nitric nitrogen represents $72 \%$ of total nitrogen. During the periods when the total nitrogen load is the same, the ratio nitric/total is 0.88 in May, 0.78 in January, 0.23 in December: it can be supposed that in December as a consequences of high rain intensities of this period (as it is reported in fig. 6) there is an high run-off from hills zone with organic nitrogen entrainment. On the contrary in May and June the less strong rain quantities follow a four months period of dry weather, and so an effective wash-out from urban areas is the origin of an higher presence of nitrates [5].

In the first months of the year, in account of the very low level of rains, the principal source of non-point input can be considered underground drainage: the underground waters in Turin show an high nitrate concentration (more than $20 \mathrm{mg} / \mathrm{l}$ ) and very low concentrations of reduced nitrogen; so it can be explained the high ratio in non-point loads. During May and June the contribution deriving from urban areas may be considered as an important aspect, as we have seen, and at the same time this effect is not compensated from a dilution effect arising from run-off surface water where the content in nitric nitrogen is lower.

During December the high rain volume determines an effect of dilution of washed nitrogen, and the same time there is an increase, as a percentage, of reduced 
Am. J. Environ. Sci., 3 (3): 98-105, 2007

Table 2 : Net non-point flow and net nitrogen non-point load (annual values)

\begin{tabular}{|c|c|c|c|c|c|}
\hline & \multirow{3}{*}{$\begin{array}{c}\text { from } \\
\text { to }\end{array}$} & I & \multirow{2}{*}{$\begin{array}{c}\text { II } \\
\text { Carignano }\end{array}$} & \multirow{2}{*}{$\begin{array}{c}\text { III } \\
\text { Moncalieri }\end{array}$} & \multirow{2}{*}{$\begin{array}{c}\text { IV } \\
\text { San Mauro }\end{array}$} \\
\hline & & Cardè & & & \\
\hline & & Carignano & Moncalieri & San Mauro & Brandizzo \\
\hline Non-point flow & $\mathrm{m}^{3} \mathrm{~s}^{-1}$ & 11 & 1.8 & 21.6 & 6.4 \\
\hline Total annual non-point flow & $m^{3} y^{-1}$ & $347 \cdot 10^{6}$ & $57 \cdot 10^{6}$ & $681 \cdot 10^{6}$ & $202 \cdot 10^{6}$ \\
\hline Linear total annual non-point flow & $\mathrm{m}^{3} \mathrm{y}^{-1} \mathrm{~km}^{-1}$ & 9.5 & 3.9 & 49.3 & 13.5 \\
\hline Non-point load of $\mathrm{N}_{\text {tot }}$ & $\mathrm{g} \mathrm{s}^{-1}$ & 66.4 & 16 & 76.4 & -13.7 \\
\hline Non-point load of $N_{\text {nitr. }}$. & $\mathrm{g} \mathrm{s}^{-1}$ & 53.2 & 2.5 & 55.1 & -9.3 \\
\hline Non-point load of $\mathrm{N}_{\mathrm{ammt}}$ & $\mathrm{g} \mathrm{s}^{-1}$ & -1.7 & 4.6 & 2 & 0.1 \\
\hline Linear non-point load of $\mathrm{N}_{\text {tot }}$ & $\mathrm{g} \mathrm{s}^{-1} \mathrm{~km}^{-1}$ & 1.81 & 1.11 & 5.54 & -0.92 \\
\hline Linear non-point load of $\mathrm{N}_{\text {nitr }}$ & $\mathrm{g} \mathrm{s}^{-1} \mathrm{~km}^{-1}$ & 1.45 & 0.17 & 3.99 & -0.62 \\
\hline Linear non-point load of $\mathrm{N}_{\text {ammt }}$ & $\mathrm{g} \mathrm{s}^{-1} \mathrm{~km}^{-1}$ & -0.046 & 0.319 & 0.145 & 0.007 \\
\hline Total annual non-point load of $\mathrm{N}_{\text {tot }}$ & $\mathrm{gy}^{-1}$ & $2094 \cdot 10^{12}$ & $505 \cdot 10^{12}$ & $2409 \cdot 10^{12}$ & $-432 \cdot 10^{12}$ \\
\hline Total annual non-point load of $\mathrm{N}_{\text {nitr }}$ & $\mathrm{g} \mathrm{y}^{-1}$ & $1678 \cdot 10^{12}$ & $79 \cdot 10^{12}$ & $1738 \cdot 10^{12}$ & $-293 \cdot 10^{12}$ \\
\hline Total annual non-point load of $\mathrm{N}_{\mathrm{amm}}$ & $\mathrm{gy}^{-1}$ & $-54 \cdot 10^{12}$ & $145 \cdot 10^{12}$ & $63 \cdot 10^{12}$ & $3 \cdot 10^{12}$ \\
\hline
\end{tabular}

nitrogen deriving from run-off from fields and exterior surfaces with high vegetation presence.

In stretch IV, in comparison with positive values for volumetric flow rates, the loads are negative for total and nitric nitrogen, negligible for reduced nitrogen; from the monthly balances of stretch IV it can be observed that only in May, September and December the sum of withdrawals from the river present higher values than contributions, whereas there are negative loads in more months for total and nitric nitrogen: this fact can be considered an index of algae uptake or biological and chemical degradation [6].

In the periods when both volumetric loads and mass loads present negative values, these phenomena can be taken into consideration; in fact if the load that can be defined by multiplying volumetric withdrawal by mean concentration parameter in the specific stretch, that can be considered emitted load, presents a lower value in comparison with the balance calculated load, this difference should represent the effectively took in or removed load; as concerns nitric nitrogen, in stretch IV we observed values of $12 \mathrm{~g} / \mathrm{s}$ in May and $36 \mathrm{~g} / \mathrm{s}$ in September; on the contrary in December the extracted load is higher than the balance value, so it was not possible to define an estimation of degradation.

In stretch I the non-point volumetric loads were all the time positive, and on the contrary reduced nitrogen loads that are in general negative; this fact is an indication of removal phenomena, in account of the streaming flow of this stretch that increases these mechanisms. By considering the total flow rate introduced in the river, and overall nitric nitrogen input, in account of general positive river contribution of this stretch, a mean concentration of non-point loads can be estimated with a value of $4.8 \mathrm{mg} / \mathrm{l}$, that is a value very similar to the characteristic value of this zone time the reduced nitrogen load is quite important. In this case a suitable explanation could be found in contributions from urban or livestock wastes, that it is impossible to evaluate. In absolute terms the introduced total and nitric nitrogen load is lower in comparison with values for upstream stretch, this fact can be explained with low values of contribution, in account of flat situation of territory and at the same time utilization of only nitric nitrogen as a fertilizer.

By using volumetric flow rate balances it was possible to identify net hydraulic input for the different considered stretches, and with mass balances we estimated nitrogen non-point loads.

The stretch corresponding to the urban zone shows higher hydraulic contributions, and also high values for total and nitric nitrogen load; for the considered year the introduced load of this stretch was $50 \%$ of the residual load introduced from city wastewater plant.

It was not possible to define the contribution to nonpoint loads of the run-off rain water that enters in the Po river through the separate sewer network of the city, also if an influence of this aspect has been identified: the definition of this contribution will require a further study activity.

We identified the presence of reduced and nitric nitrogen removal mechanisms chiefly in the stretch downstream from the city, and only in this stretch for nitric nitrogen load negative values have been obtained. On the basis of these observations, some general indications of the present work can be drawn:

- from the point of view of phenomena estimation and data acquisition, it is necessary to improve sampling points, both from the point of view of hydraulic data and also as concerns concentrations, and to give a systematic approach to this scheme of 
data collection, in order to can be able to efficiently use information;

- from the point of view of phenomena comprehension, it was possible to identify some important impact transfer aspects from the river banks, and dynamic transformations in the river, that can be useful for a better approach to river modeling for this stretch;

- from the point of view of public policy, the information about potential non-point transfer phenomena from the surrounding territories or from urban zones can support decisions of public authorities in terms of better agricultural policies or urban sewer network assessment, in order to better protect the water resource.

\section{REFERENCES}

1. Rosselli A., 2004. Verifica di un impianto di denitrificazione. Politecnico di Torino, Tesi di laurea
2. Gerda van Dijk, M., L. van Liere, W. Admiral,B.A. Bannink, J.J. Cappon, 1994. Present state of the water quality of European rivers and implication for management. The Science of the Total Environment,145,: 182-195.

3. Rauch, W., M. Henze, L. Koncsos, et al, 1998. River water quality modeling : State of the art. Water Science Technology, 38, (11) : 237-244.

4. Marchetti, R., N. Verna, 1990. Valutazione dei carichi teorici di fosforo e di azoto dei bacini costieri dell'Emilia Romagna. Acqua Aria, 1 : 4145

5. Capodaglio, A., V. Novotny, S. Zheng, 1990. Modello di simulazione dell'inquinamento diffuso di origine urbana per il bacino della laguna di Venezia. Ingegneria Ambientale, XIX, (9) : 563573.

6. Warwick, J.J. and A.J. McDonnell, 1985. Simultaneous in stream nitrogen and DO balancing. ASCE, Journal of Environmental Engineering, III, (4): 401-430 